\title{
Health economics perspective of fesoterodine, tolterodine or solifenacin as first-time therapy for overactive bladder syndrome in the primary care setting in Spain
}

Antoni Sicras-Mainar ${ }^{1 *}$, Javier Rejas ${ }^{2}$, Ruth Navarro-Artieda ${ }^{3}$, Alba Aguado-Jodar ${ }^{4}$, Amador Ruiz-Torrejón ${ }^{5}$, Jordi Ibáñez-Nolla ${ }^{6}$ and Marion Kvasz ${ }^{7}$

\begin{abstract}
Background: Overactive bladder (OAB) is associated with high healthcare costs, which may be partially driven by drug treatment. There is little comparative data on antimuscarinic drugs with respect to resource use and costs. This study was conducted to address this gap and the growing need for naturalistic studies comparing health economics outcomes in adult patients with $\mathrm{OAB}$ syndrome initiating treatment with different antimuscarinic drugs in a primary care setting in Spain.

Methods: Medical records from the databases of primary healthcare centres in three locations in Spain were assessed retrospectively. Men and women $\geq 18$ years of age who initiated treatment with fesoterodine, tolterodine or solifenacin for OAB between 2008 and 2010 were followed for 52 weeks. Healthcare resource utilization and related costs in the Spanish National Health System were compared. Comparisons among drugs were made using multivariate general linear models adjusted for location, age, sex, time since diagnosis, Charlson comorbidity index, and medication possession ratio.
\end{abstract}

Results: A total of 1,971 medical records of patients (58.3\% women; mean age, 70.1 [SD:10.6] years) initiating treatment with fesoterodine $(n=302)$, solifenacin $(n=952)$ or tolterodine $(n=717)$ were examined. Annual mean cost per patient was $€ 1798$ (95\% Cl: $€ 1745 ; € 1848)$. Adjusted mean (95\% bootstrap Cl) healthcare costs were significantly lower in patients receiving fesoterodine (€1639 [1542; 1725]) compared with solifenacin (€1780 [€1699; €1854], $P=0.022$ ) or tolterodine (€1893 [€1815; €1969], $P=0.001$ ). Cost differences occurred because of significantly fewer medical visits, and less use of absorbent products and OAB-related concomitant medication in the fesoterodine group.

Conclusions: Compared with solifenacin and tolterodine, fesoterodine was a cost-saving therapy for treatment of $O A B$ in the primary care setting in Spain.

Keywords: Antimuscarinics, Overactive bladder, Costs, Primary care setting, Health resources

\section{Background}

Overactive bladder $(\mathrm{OAB})$ is a syndrome characterized by symptoms of urinary urgency, with or without urge incontinence, often accompanied by daytime frequency and nocturia. It is caused by an overactive detrusor muscle and may be accompanied by neurological dysfunction [1-3].

\footnotetext{
*Correspondence: asicras@bsa.cat

${ }^{1}$ Directorate of Planning, Badalona Serveis Assistencials SA, Calle Gaietà Soler, 6-8 entlo, CP 08911 Badalona, Barcelona, Spain

Full list of author information is available at the end of the article
}

The prevalence in adults ranges between $10 \%$ and $20 \%$ and increases with age [4-6]. In Europe the prevalence in the general population $>18$ years of age is $11.8 \%$ and is similar for men and women $[4,7,8]$. In Spain the population-based EPICC study estimated the prevalence of OAB to be $21.5 \%$ in adults $\geq 40$ years of age and $38.5 \%$ in institutionalized people $\geq 65$ years of age $[9,10]$. OAB has a negative effect on quality of life in affected individuals, which results from both the characteristic symptoms of OAB syndrome as well as the coping strategies frequently adopted to

\section{Biomed Central}

(C) 2013 Sicras-Mainar et al.; licensee BioMed Central Ltd. This is an open access article distributed under the terms of the Creative Commons Attribution License (http://creativecommons.org/licenses/by/2.0), which permits unrestricted use, distribution, and reproduction in any medium, provided the original work is properly cited. 
reduce symptom impact $[11,12]$. People often take extreme measures to reduce urinary frequency and episodes of incontinence, which significantly impacts their physical health, vitality, social life, emotional state and functionality [13-15]. Many individuals do not seek professional help for OAB symptoms and only a quarter receive treatment $[5,16,17]$.

Pharmacological treatment of $\mathrm{OAB}$ aims to decrease involuntary contractions of the detrusor muscle of the bladder by blocking the bladder receptors with antimuscarinic drugs [18-21]. Efficacy, safety, and tolerability [22-26] as well as improved health-related quality of life [27] have been demonstrated in clinical studies for the antimuscarinics fesoterodine, tolterodine and solifenacin. However little is known about how these findings from clinical trials extrapolate to the heterogeneous populations seen in primary practice. Several studies indicate that realworld adherence is low and is typically attributed to a perceived lack of efficacy or tolerability issues [28,29].

$\mathrm{OAB}$ is associated with high direct healthcare costs [30-32]. Factors contributing to the cost of OAB include drug treatment, physician visits, hospitalizations and laboratory tests. Evidence comparing antimuscarinic drugs with respect to resource use and costs is limited, and totally lacking from a Spanish National Health System (NHS) perspective. To address this gap and the growing need for naturalistic multicenter studies, this study was conducted to compare healthcare resource utilization and related costs in patients initiating treatment with fesoterodine, tolterodine, or solifenacin for the treatment of OAB syndrome in the primary care setting in a representative sample of the Spanish NHS.

\section{Methods}

\section{Design and objectives}

In this observational, multicenter, post-marketing, longitudinal, retrospective study, existing medical records (computerized databases with de-identified data) of outpatients and inpatients with a diagnostic code of $O A B$ in three different locations in Spain were extracted and reviewed.

The main objectives of the study were to compare healthcare resource utilization related to the clinical management of $\mathrm{OAB}$ syndrome and corresponding costs in patients treated with fesoterodine, tolterodine, or solifenacin for the first time in the primary care setting in Spain's NHS.

\section{Study population}

The study population consisted of patients from three geographical areas of two autonomous regions (Catalonia [Badalona and Barcelona locations] and the Balearic Islands [Mallorca]). These regions were selected because of the existence of available healthcare provider databases and because one region (Catalonia) is continental and large while the other (the Balearic Islands) is insular and small, meaning that the varied geographical composition of the country is reflected in the study and thus may be considered representative of Primary Care settings in Spain. Eighteen primary health care centres (PHC), 7 in Badalona, 2 in Barcelona and 9 in Mallorca, and their corresponding referral hospitals (three) participated in the study. The population assigned to these centres is mostly urban and industrial and low- to middle-class socioeconomic status. The follow-up period was 52 weeks from the initiation date of antimuscarinic treatment (index date).

Eligible men and women were $\geq 18$ years of age who had not received any antimuscarinic therapy for $\geq 1$ year before the index date; who sought medical care and initiated treatment with fesoterodine, tolterodine or solifenacin during the recruitment period (1 January 2008 to 31 December 2010); who received treatment within the designated healthcare system area; who were followed up regularly as demonstrated by $\geq 2$ computerized health records in the corresponding health area; and who participated in a prescription drug program. Patients who transferred to other primary care centres, regions, or health areas; who were treated simultaneously with $\geq 2$ antimuscarinic drugs during the study period; or who were permanently institutionalized were excluded. Sampling of medical records was exhaustive without reposition among those meeting eligibility criteria for the study.

\section{Database information}

Clinical data on patients treated with fesoterodine, tolterodine or solifenacin (Anatomical Therapeutic Chemical Classification System [33]) were obtained from claim databases using the same informatics system for filing and handle health data (ONMI-AP software). These databases are owned by Badalona Serveis Assistencials (BSA), a healthcare provider in Badalona (Barcelona), Sagrada Familia Primary Care Health Centre in Barcelona Spain, and the Primary Health Care Directorate of ib-Salut, the healthcare provider for Mallorca. The choice of specific medicine and dose was determined by the patients' physicians as part of routine primary care. Data on prescribed doses of fesoterodine (4 and $8 \mathrm{mg}$ ), solifenacin (5 and $10 \mathrm{mg}$ ) and tolterodine (2 and $4 \mathrm{mg}$ ) and treatment time (in weeks) during follow-up were recorded in the database.

\section{Compliance}

Compliance, as defined by the International Society for Pharmacoeconomics and Outcomes Research working group, was computed using the medication possession ratio (MPR) [34]. The MPR is measured from first to last prescription and represents the number of days of medication supplied divided by number of days the patient was followed (starting with the index date) [35]. The MPR is 
viewed as a proxy of compliance because compliance may be overestimated by simply summing the number of days' supply; patients may refill medication before finishing the current fill.

\section{Definition of overactive bladder and co-morbidities included in the study}

The diagnosis of $\mathrm{OAB}$ was confirmed in enrolled patients using the International Classification of Primary Care (ICPC-2), component 7; diseases and health problems [36] (U13), and hospital and emergency room discharge coding, according to the International Classification of Diseases, 9th Revision, Clinical Modification, ICD-9-CM (596.51). The main study variables were: age (continuous and ranges), sex, occupational status (active, retired), time from diagnosis until treatment initiation and personal history (ICPC-2) of hypertension (K86, K87), diabetes mellitus (T89, T90), dyslipidemia (T93), obesity (T82), smoking (P17), alcoholism (P15, P16), all types of organ failure (cardiac, hepatic and renal), cerebrovascular accident (K90, K91, K93), chronic obstructive pulmonary disease (R95, chronic airflow obstruction), bronchial asthma (R96), dementia or memory disorders (P70, P20), neurological diseases: (Parkinson's disease [N87], epilepsy [N88], multiple sclerosis [N86] and other neurological diseases [N99]), depressive syndrome (P76) and malignant neoplasms (all types, A79, B72-75, D74-78, F75, H75, K72, L71, L97, N74-76, R84-86, T71-73 , U75-79, W72-73, X75-81, Y77-79). The Charlson comorbidity index [37] was used to summarize each patient's comorbidity status as well as the number of chronic co-morbidities.

\section{Resource use and cost analysis}

Healthcare costs for this study were defined as all OABrelated costs, including medical care visits (primary care, specialty care [urology and gynaecology] and emergency room), days of hospitalization, and all OAB-related diagnostic or therapeutic tests (with or without urinary incontinence) performed by health professionals. Costs were expressed as the annual mean cost per patient (unit/cost) for fesoterodine, tolterodine or solifenacin treatment. A full list of resources collected and associated unit costs are shown in Table 1. Year 2011 prices were used to compute unit costs. Use of absorbent products for urinary incontinence and concomitant medications associated with the potential clinical consequences of $\mathrm{OAB}$ were included in estimated costs. Concomitant drugs of interest included antidepressants, anxiolytics, hypnotics, antibiotics, and antiseptics for urinary tract and/or skin infections (systemic or topical) and laxatives used for the treatment of antimuscarinic-related constipation. Costs of acute, chronic and on-demand prescriptions were calculated using the retail price per pack at the time of prescribing. Direct non-health costs (disease-associated out-of-pocket
Table 1 Unit costs of resources utilized

\begin{tabular}{|c|c|}
\hline Health and non-health resources & 2011 Unit costs $(€)$ \\
\hline \multicolumn{2}{|l|}{ Medical visits } \\
\hline Primary care & 23.19 \\
\hline Emergency room & 117.53 \\
\hline Specialist & 104.41 \\
\hline \multicolumn{2}{|l|}{ Complementary tests* } \\
\hline Laboratory tests $^{\dagger}$ & 22.30 \\
\hline Conventional radiology ${ }^{\ddagger}$ & 18.50 \\
\hline Diagnostic/therapeutic tests* & 37.12 \\
\hline Drug prescription ${ }^{\S}$ & Retaill $^{\prime \prime}$ \\
\hline Hospitalization (one day in a general ward) & 320.90 \\
\hline \multicolumn{2}{|c|}{$\begin{array}{l}\text { Information sources: study site cost accounting and Spanish National Institute } \\
\text { of Statistics. } \\
\text { *Includes ultrasound scans or other diagnostic imaging tests } \\
\text { and electrocardiograms. } \\
{ }^{\dagger} \text { Includes blood count, biochemistry, lipid panel, urinalysis, thyroid function. } \\
{ }^{\ddagger} \text { Includes X-ray measurements. } \\
{ }^{\S} \text { Includes the costs of antimuscarinic drugs, absorbent products and concomitant } \\
\text { medications (antidepressants, anxiolytics, antibiotics, anti-infective drugs, laxatives } \\
\text { and dermatologic products for skin infections). } \\
\text { "Retail: retail price + value added tax (for year 2011). }\end{array}$} \\
\hline
\end{tabular}

costs paid by patients and their families) were not included in the study because these are not captured in the database, and the database does not provide direct access to patients. Overall costs by drug were assessed for a 52-week follow-up period. Baseline healthcare resource use and associated costs were also determined for 1 year prior to antimuscarinic initiation.

\section{Data confidentiality and ethics statement}

This was a retrospective observational study using existing data on patients included in a claim database. Data confidentiality was respected at all times by means of de-identification thus ensuring anonymity according to Spanish Organic Law (Law 15/1999 of 13 December on the Protection of Personal Data). Thus no data which could reveal patient identity was extracted. The database was then prepared and closed for statistical analysis, not allowing further manipulation of data. The study, its design and procedures was classified by the Spanish Medicines Agency (AEMPS) as a Post-Authorisation Study - Other Designs (EPA-OD) trial type and was subsequently approved by the Clinical Research Ethics Committee of Hospital Clinic I Provincial of Barcelona. Based on its design, it was exempt under Spanish law from requiring written informed consent (Law 29/2006 of 26 July and Royal Decree 1344/2007 of 11 October; see http://www.aemps.gob.es/investigacion Clinica/medicamentos/estudiosPostautorizacion.htm).

\section{Statistical analysis}

In this population-based study, the sample size was calculated according to an expected prevalence of $\mathrm{OAB}$ of 
$15 \%$ in the country, assuming a random error of $5 \%$ and an estimated precision of $2 \%$. The study required medical records in a 1:2:2 proportion for fesoterodine, solifenacin and tolterodine, respectively, to match the expected distribution of use of these drugs on the Spanish market. A minimum of 300:600:600 medical records (one record per patient) were necessary to be able to detect a difference in healthcare costs of $€ 260$ (standard error, 71) between two drugs with an $\alpha$ level of $<0.05$ (with degree of freedom corrected after applying a Bonferroni adjustment for multiple comparisons) and a minimum power of $80 \%$.

Computerized medical records were assessed for frequency distributions as well as possible errors in registration or coding. Descriptive univariate statistical analyses were performed, using the mean, median, standard deviation and 95\% confidence intervals (CI) for parametric variables and the median and interquartile ranges (25 and 75 percentiles of the distribution) for non-parametric variables, after verifying the normality of the distribution with the Kolmogorov-Smirnov test. Two-sample comparisons were performed for all variables with location as a grouping variable to confirm homogeneity of data across study locations (Badalona, Barcelona and Mallorca). Although no clinically relevant differences were noted, location was included as a covariate in all subsequent analyses. Persistence with antimuscarinic treatment was initially analyzed descriptively by calculating the proportion of patients who remained on treatment during the 52-week period following the index date.

Resource utilization and costs were compared using robust analysis of variance (ANOVA) tests (Welch test and Brown-Forsythe test with a subsequent pairing of contrasts using the Games-Howell test) and the chisquare test, and depending on the distribution of the data, a bivariate analysis, without controlling for possible confounding variables. Resource utilization and the associated costs were compared according to the recommendations of Thompson and Barber [38], using a multivariate general linear model controlling for the following covariates: location, age, sex, MPR, time since diagnosis and disease burden. Disease burden included the number of comorbid diagnoses and the Charlson comorbidity index. Pairwise comparisons were adjusted using the procedure for estimating marginal means, applying the Bonferroni correction to estimate the $P$ value of statistical significance. The data are presented as adjusted mean differences between treatments with corresponding 95\% CIs calculated using re-sampling techniques (bootstrapping) corrected for bias, given the non-normal distributions of the variables with respect to resource utilization and costs. The analysis was performed using the statistical package SPSS for Windows version 19. Statistical significance was established as $P<0.05$, all tests were 2 -sided.
Unit drug costs were obtained from prices listed at the time of prescription, which is an approximation because drug prices may have varied during follow-up. We performed a secondary analysis by applying a $40 \%$ reduction in the cost of tolterodine and $7.5 \%$ reduction in the costs of solifenacin and fesoterodine. The $40 \%$ reduction in the price of tolterodine is justified by the recent ( $3^{\text {rd }}$ quarter 2012) loss of exclusivity of this drug; the reduction was applied to the price at the time described above. The $7.5 \%$ reduction in the price of fesoterodine and solifenacin is justified by the discount applicable to these active principles set in Royal Decree RD 8/2010 of 20 May.

\section{Results}

Of the 170,880 patients regularly seen at the study sites, 2778 patients initiated $\mathrm{OAB}$ treatment during the study period. Of these, 1971 met the study criteria and were enrolled (Figure 1). Of these, 952 (48.3\%) were treated with solifenacin, 717 (36.4\%) with tolterodine and 302 (15.3\%) with fesoterodine. Patients treated with tolterodine were significantly older and included significantly more females compared with solifenacin and fesoterodine (Table 2). However disease burden, assessed by the number of comorbid diagnoses and the Charlson comorbidity index, was similar in the 3 groups. The mean time from diagnosis to initiation of antimuscarinic treatment and

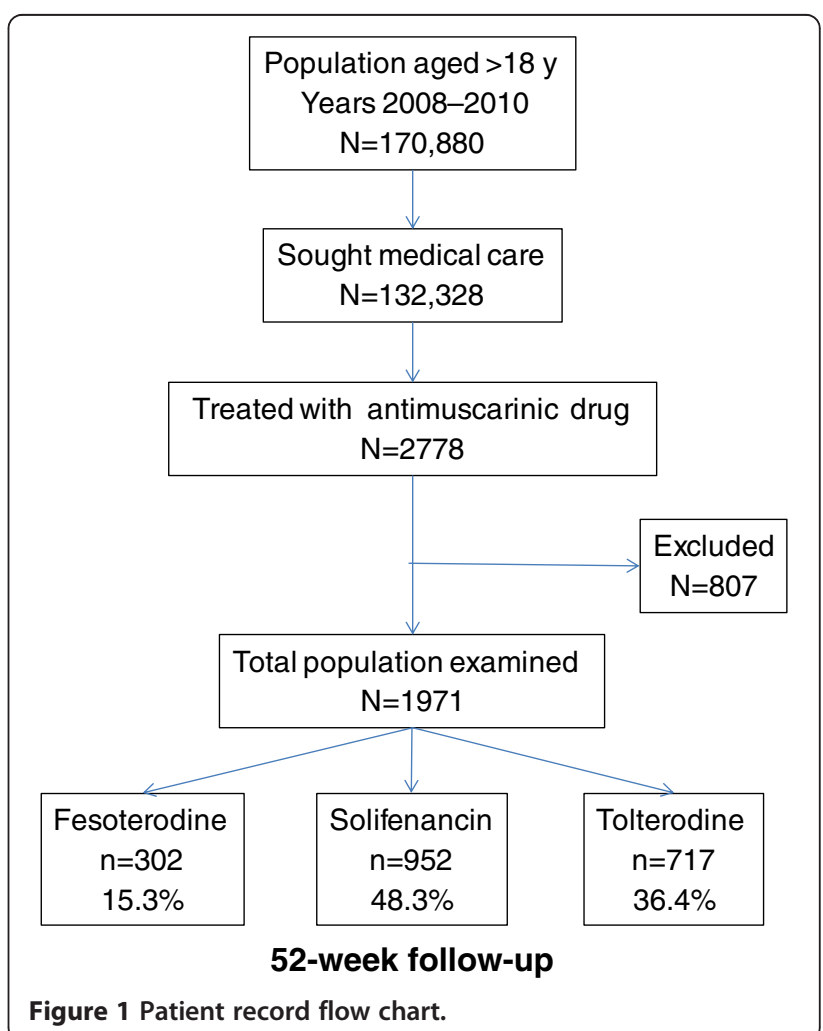


Table 2 Demographic and clinical characteristics by type of antimuscarinic drug

\begin{tabular}{|c|c|c|c|c|}
\hline \multirow[t]{2}{*}{ Characteristics } & \multicolumn{3}{|c|}{ Antimuscarinic } & \multirow[b]{2}{*}{$\begin{array}{l}\text { Overall } \\
P \text { Value }\end{array}$} \\
\hline & $\begin{array}{l}\text { Fesoterodine } \\
\qquad(\mathrm{n}=302)\end{array}$ & $\begin{array}{c}\text { Solifenacin } \\
(\mathrm{n}=952)\end{array}$ & $\begin{array}{l}\text { Tolterodine } \\
(\mathrm{n}=717)\end{array}$ & \\
\hline \multicolumn{5}{|l|}{ Demographics } \\
\hline Mean age, years (SD) & $67.5(11.0)$ & $69.7(10.8)^{*}$ & $71.7(9.8)^{*^{\dagger}}$ & $<0.001$ \\
\hline Female, n (\%) & $156(51.7)$ & $562(59.0)$ & $432(60.3)^{\ddagger}$ & 0.036 \\
\hline Retired, n (\%) & $254(84.1)$ & $836(87.8)$ & $673(93.8)^{*^{\dagger}}$ & $<0.001$ \\
\hline \multicolumn{5}{|l|}{ Burden of comorbidity } \\
\hline Associated diagnoses, n (\%) & $2.6(1.7)$ & $2.8(1.7)$ & $2.8(1.5)$ & 0.135 \\
\hline Charlson comorbidity index, mean (SD) & $1.2(1.3)$ & $1.2(1.3)$ & $1.3(1.4)$ & 0.230 \\
\hline Score, n (\%) & & & & 0.326 \\
\hline $0-1$ & $228(75.5)$ & $703(73.8)$ & $516(72.0)$ & \\
\hline $2-3$ & $50(16.6)$ & $166(17.4)$ & $120(16.7)$ & \\
\hline$\geq 4$ & $24(7.9)$ & $83(8.7)$ & $81(11.3)$ & \\
\hline \multicolumn{5}{|l|}{ Associated co-morbidities, n (\%) } \\
\hline Hypertension & $142(47.0)$ & $494(51.9)$ & $413(57.6)^{\ddagger}$ & 0.004 \\
\hline Diabetes & $62(20.5)$ & $233(24.5)$ & $178(24.5)$ & 0.304 \\
\hline Dyslipidemia & $148(49.0)$ & $454(47.7)$ & $385(53.7)^{\ddagger}$ & 0.048 \\
\hline Obesity & $66(21.9)$ & $204(21.4)$ & $147(20.5)$ & 0.854 \\
\hline Active smoker & $44(14.6)$ & $140(14.7)$ & $69(9.6)^{\dagger \ddagger}$ & 0.006 \\
\hline Alcoholism & $13(4.3)$ & $22(2.3)$ & $16(2.2)$ & 0.124 \\
\hline Ischemic heart disease & $34(11.3)$ & $114(12.0)$ & $77(10.7)$ & 0.731 \\
\hline Cerebrovascular accident & $44(14.6)$ & $135(14.2)$ & $119(16.6)$ & 0.378 \\
\hline Organ failure & $34(11.3)$ & $132(13.9)$ & $87(12.1)$ & 0.389 \\
\hline Bronchial asthma & $32(10.6)$ & $104(10.9)$ & $64(8.9)$ & 0.393 \\
\hline COPD & $34(11.3)$ & $125(13.1)$ & $93(13.0)$ & 0.685 \\
\hline Dementia (all types) & $25(8.3)$ & $88(9.2)$ & 78 (10.9) & 0.357 \\
\hline Neuropathies & $33(10.9)$ & $100(10.5)$ & $82(11.4)$ & 0.833 \\
\hline Depressive syndrome & $20(6.6)$ & $86(9.0)$ & $69(9.6)$ & 0.298 \\
\hline Malignant neoplasms & $64(21.2)$ & $216(22.7)$ & $159(22.3)$ & 0.862 \\
\hline \multicolumn{5}{|l|}{ Treatment duration and dose, mean (SD) } \\
\hline Time since $O A B$ diagnosis, years & $4.4(1.8)$ & $4.8(1.9)^{\ddagger}$ & $4.5(1.8)^{\S}$ & 0.023 \\
\hline Observed treatment duration, weeks & $35.5(17.6)$ & $33.9(21.4)$ & $33.0(21.6)$ & 0.160 \\
\hline Medication possession ratio, $\%$ & $94.5(8.4)$ & $95.4(8.3)$ & $94.6(8.7)$ & 0.053 \\
\hline Number of antimuscarinics" & $1.0(0.2)$ & $1.0(0.2)$ & $1.1(0.3)^{\S}$ & $<0.001$ \\
\hline \multicolumn{5}{|l|}{ Antimuscarinic dose, n (\%) } \\
\hline $2 \mathrm{mg}$ & & & $86(12.0)$ & \\
\hline $4 \mathrm{mg}$ & $131(43.4)$ & --- & $631(88.0)$ & \\
\hline $8 \mathrm{mg}$ & $171(56.6)$ & --- & --- & \\
\hline $5 \mathrm{mg}$ & --- & $828(87.0)$ & --- & \\
\hline $10 \mathrm{mg}$ & --- & $74(13.0)$ & --- & \\
\hline
\end{tabular}

$\mathrm{COPD}=$ chronic obstructive pulmonary disease $\mathrm{OAB}=$ overactive bladder.

${ }^{*} P<0.001$ vs fesoterodine.

${ }^{\dagger} P<0.01$ vs solifenacin.

${ }^{\ddagger} P<0.01$ vs fesoterodine.

${ }^{\S} P<0.001$ vs solifenacin.

"During 52 weeks of follow-up. 
the MPR were significantly higher with solifenacin compared with tolterodine and fesoterodine. The mean duration of antimuscarinic treatment was numerically higher for fesoterodine, but no statistical differences were found among drugs. The most commonly prescribed doses were fesoterodine $8 \mathrm{mg}$, solifenacin $5 \mathrm{mg}$ and tolterodine $4 \mathrm{mg}$. A higher percentage of patients treated with tolterodine, compared with fesoterodine or solifenacin, were prescribed a second antimuscarinic treatment during the study period (7.9\% vs $4.3 \%$ and $3.6 \%$, respectively; $P=0.001)$.

No statistically significant differences were found in pre-treatment costs among treatment groups. Costs for outpatient visits, analytical tests, radiology, laboratory tests, hospitalization days and absorbent products used were not significantly different by antimuscarinic group prior to the study.

Compared with patients treated with solifenacin and tolterodine, patients treated with fesoterodine used significantly fewer antidepressants (Table 3), including selective serotonin reuptake inhibitors (SSRIs) and serotonin-norepinephrine reuptake inhibitors (SNRIs). Use of antibiotics/antiseptics was significantly lower in patients receiving fesoterodine or solifenacin compared with tolterodine $(P<0.001$ for both). Fesoterodine was associated with decreased use of benzodiazepines/hypnotics and laxatives, although differences were not significant.

After adjusting for covariates, patients treated with fesoterodine had fewer outpatient medical visits of any type compared with solifenacin and tolterodine (13.2 vs. 15.1 and 16.4, respectively; $P<0.001$ ), including primary care (11.6 vs. 12.9 and $14.2, P<0.001)$, specialist (1.5 vs. 2.0 and $2.0, P<0.001$ ), and emergency room ( 0.1 vs. 0.2 and $0.3, P<0.001$ ) visits (Table 4 ). Differences in use of analytical and complementary tests, $\mathrm{x}$-rays, and days of hospitalization were not significant. Patients treated with fesoterodine had significantly lower healthcare costs versus those receiving solifenacin and tolterodine: $€ 1639$ vs $€ 1780$ and $€ 1893$, respectively $(P=0.003$; Table 5$)$, despite significantly higher drug costs for fesoterodine ( $€ 740$ vs $€ 626$ and $€ 624 ; P<0.001$ ). Fesoterodine-treated patients incurred significantly lower costs for outpatient visits compared with solifenacin-treated and tolterodinetreated patients ( $€ 433$ vs $€ 533$ and $€ 563$, respectively, $P<0.001$ ), especially in primary care ( $€ 268$ vs $€ 300$ and $€ 329, P<0.001$ ); concomitant medication expenses were significantly lower with fesoterodine ( $€ 216$ vs $€ 305$ and $€ 335, \mathrm{p}<0.001)$. Treatment differences in adjusted costs of radiology, analytic, and complementary tests and days of hospitalization were not significant. Adjusted total healthcare costs were significantly higher in patients receiving tolterodine compared with those treated with fesoterodine $(P<0.05$; Table 5$)$.

In a secondary analysis in which drug prices were assumed to be those currently set by the NHS (Figure 2), the trends observed in healthcare costs were similar to those described in the primary analysis. Total healthcare costs were similar for patients treated with fesoterodine and tolterodine, despite the $40 \%$ reduction in the price of tolterodine. Both fesoterodine and tolterodine were associated with significantly lower total healthcare costs than solifenacin.

\section{Discussion and conclusion}

There are few reports detailing healthcare resource utilization and corresponding costs in routine clinical practice with antimuscarinics. This study indicates that fesoterodine treatment for $\mathrm{OAB}$ was associated with lower

Table 3 Percentage of patients using OAB-related concomitant medications during follow-up by antimuscarinic drug

\begin{tabular}{|c|c|c|c|c|c|}
\hline \multirow[t]{2}{*}{ Concomitant medication } & \multicolumn{3}{|c|}{ Antimuscarinic } & \multirow[b]{2}{*}{$\begin{array}{c}\text { Overall } \\
(N=1971)\end{array}$} & \multirow[b]{2}{*}{$\begin{array}{c}\text { Overall } \\
P \text { Value* }\end{array}$} \\
\hline & $\begin{array}{l}\text { Fesoterodine } \\
\qquad(n=302)\end{array}$ & $\begin{array}{l}\text { Solifenacin } \\
(n=952)\end{array}$ & $\begin{array}{c}\text { Tolterodine } \\
(\mathrm{n}=717)\end{array}$ & & \\
\hline Antidepressants & 31.8 & $42.6^{\dagger}$ & $57.9^{1 \neq}$ & 45.6 & $<0.001$ \\
\hline Tricyclics & 9.2 & 9.1 & 7.4 & 8.6 & 0.610 \\
\hline SSRIs & 16.9 & $23.3^{\S}$ & $35.5^{\dagger \neq}$ & 26.1 & $<0.001$ \\
\hline SNRIS & 18.5 & $26.3^{11}$ & $37.4^{\dagger \neq}$ & 28.5 & $<0.001$ \\
\hline Benzodiazepines/hypnotics & 49.2 & 53.5 & $58.1^{\S}$ & 54.2 & 0.012 \\
\hline Antibiotics/antiseptics & 20.5 & 20.4 & $35.5^{\dagger \neq}$ & 25.2 & $<0.001$ \\
\hline Laxatives & 19.5 & 21.9 & 23.0 & 21.8 & 0.638 \\
\hline Dermatological products & 21.5 & 21.8 & 20.2 & 21.2 & 0.847 \\
\hline
\end{tabular}

SSRIs = selective serotonin reuptake inhibitors; SNRIs = serotonin-norepinephrine reuptake inhibitors.

${ }^{*}$ Controlling for location, age, sex, medication possession ratio, time since diagnosis and Charlson co-morbidity index.

${ }^{\dagger} P<0.001$ vs fesoterodine.

${ }^{\ddagger} P<0.001$ vs solifenacin.

${ }^{\S} P<0.05$ vs fesoterodine.

$\| P<0.01$ vs fesoterodine. 
Table 4 Use of healthcare resources per patient per year according to antimuscarinic treatment in adjusted analysis*

\begin{tabular}{|c|c|c|c|c|}
\hline \multirow[t]{2}{*}{ Resource, mean $\left(95 \% \mathrm{Cl}^{\dagger}\right)$} & \multicolumn{3}{|c|}{ Antimuscarinic } & \multirow[b]{2}{*}{$P$ Value } \\
\hline & $\begin{array}{l}\text { Fesoterodine } \\
\qquad(n=302)\end{array}$ & $\begin{array}{l}\text { Solifenacin } \\
\qquad(n=952)\end{array}$ & $\begin{array}{c}\text { Tolterodine } \\
(n=717)\end{array}$ & \\
\hline Medical visits, $n$ & $13.2(12.3 ; 14.1)$ & $15.1(14.5 ; 15.9)^{\ddagger}$ & $16.4(15.5 ; 17.5)^{\neq \S}$ & $<0.001$ \\
\hline Primary care & $11.6(10.8 ; 12.5)$ & $12.9(12.2 ; 13.7)^{\|}$ & $14.2(13.2 ; 15.3)^{\ddagger}$ & 0.006 \\
\hline Specialist & $1.5(1.4 ; 1.6)$ & $2.0(2.0 ; 2.1)^{\ddagger}$ & $2.0(1.9 ; 2.0)^{\ddagger}$ & $<0.001$ \\
\hline Emergency room & $0.1(0.1 ; 0.1)$ & $0.2(0.2 ; 0.2)^{\ddagger}$ & $0.3(0.3 ; 0.3)^{ \pm \uparrow}$ & $<0.001$ \\
\hline Analytical tests, $\mathrm{n}$ & $0.8(0.7 ; 0.9)$ & $0.7(0.7 ; 0.8)$ & $0.7(0.6 ; 0.8)$ & 0.686 \\
\hline X-ray, n & $0.3(0.3 ; 0.4)$ & $0.4(0.3 ; 0.4)$ & $0.4(0.4 ; 0.5)$ & 0.157 \\
\hline Complementary tests, $\mathrm{n}$ & $0.2(0.1 ; 0.3)$ & $0.2(0.1 ; 0.2)$ & $0.2(0.1 ; 0.3)$ & 0.849 \\
\hline Hospital stays, days & $0.1(0.1 ; 0.2)$ & $0.2(0.1 ; 0.2)$ & $0.2(0.1 ; 0.2)$ & 0.221 \\
\hline
\end{tabular}

${ }^{*}$ Adjusting for geographic area, age, sex, medication possession ratio, time since diagnosis and Charlson co-morbidity index.

${ }^{\dagger} 95 \%$ bootstrap confidence interval bias corrected.

${ }^{\ddagger} P<0.01$ vs fesoterodine.

${ }^{\S} P<0.05$ vs solifenacin.

$\| P<0.05$ vs fesoterodine.

${ }^{\mathrm{I}} P<0.001$ vs solifenacin.

healthcare resource use than solifenacin or tolterodine treatment, and therefore lower average costs per patient, in routine clinical practice in the Spanish NHS. The treatment groups were comparable at baseline, as indicated by burden of comorbidity and duration of antimuscarinic treatment. There were no significant differences in resource use and costs incurred during the year preceding the index date; baseline costs per patient were lower because no antimuscarinics were prescribed and patients were not actively followed for OAB. This study included a large sample of medical records from three different geographic regions of Spain. Our findings did not vary by location and thus are likely generalizable throughout Spain.

Antimuscarinic cost was higher in patients treated with fesoterodine because a greater proportion of patients received the higher dose and had a longer duration of use compared with patients treated with solifenacin and

Table 5 Adjusted* healthcare cost (€) per patient per year by antimuscarinic drug

\begin{tabular}{|c|c|c|c|c|}
\hline \multirow[t]{2}{*}{ Resource, mean $\left(95 \% \mathrm{Cl}^{\dagger}\right)$} & \multicolumn{3}{|c|}{ Antimuscarinic } & \multirow[b]{2}{*}{$P$ Value* } \\
\hline & $\begin{array}{l}\text { Fesoterodine } \\
\qquad(n=302)\end{array}$ & $\begin{array}{c}\text { Solifenacin } \\
(\mathrm{n}=952)\end{array}$ & $\begin{array}{c}\text { Tolterodine } \\
(n=717)\end{array}$ & \\
\hline Medical visits & $433(411 ; 457)$ & $533(515 ; 552)^{\ddagger}$ & $563(539 ; 585)^{\neq \S}$ & $<0.001$ \\
\hline Primary care & $268(249 ; 290)$ & $300(284 ; 319)^{\|}$ & $329(305 ; 353)^{\ddagger \S}$ & 0.005 \\
\hline Specialist & $152(144 ; 162)$ & $212(208 ; 216)^{\ddagger}$ & $204(200 ; 207)^{\xi \uparrow}$ & $<0.001$ \\
\hline Emergency room & $12(10 ; 16)$ & $21(19 ; 24)^{\ddagger}$ & $30(27 ; 33)^{\text {sq }}$ & $<0.001$ \\
\hline Analytical tests & $18(15 ; 20)$ & $17(15 ; 18)$ & $16(14 ; 18)$ & 0.686 \\
\hline X-ray & $6(5 ; 8)$ & $7(6 ; 7)$ & $8(7 ; 9)$ & 0.157 \\
\hline Complementary tests & $7(5 ; 10)$ & $7(5 ; 8)$ & $8(5 ; 10)$ & 0.849 \\
\hline Hospital stays & $35(19 ; 59)$ & $46(33 ; 63)$ & $53(41 ; 70)$ & 0.509 \\
\hline Antimuscarinic drugs & $740(690 ; 796)$ & $626(602 ; 652)^{\ddagger}$ & $624(597 ; 650)^{\ddagger}$ & $<0.001$ \\
\hline Concomitant medication $^{\#}$ & $216(180 ; 258)$ & $305(274 ; 338)^{\ddagger}$ & $335(306 ; 366)^{\ddagger}$ & 0.001 \\
\hline Absorbents & $187(135 ; 244)$ & $243(201 ; 290)$ & $289(237 ; 344)^{\| \prime}$ & 0.094 \\
\hline Total healthcare costs & $1639(1542 ; 1725)$ & $1780(1699 ; 1854)^{\| \prime}$ & $1893(1815 ; 1969)^{\neq \S}$ & 0.003 \\
\hline
\end{tabular}

${ }^{*}$ Controlling for location, age, sex, medication possession ratio, time since diagnosis and Charlson co-morbidity index

${ }^{\dagger} 95 \%$ bootstrap confidence interval bias corrected.

${ }^{\ddagger} P<0.01$ vs fesoterodine.

${ }^{\S} P<0.05$ vs solifenacin.

$\| P<0.05$ vs fesoterodine.

" $P<0.01$ vs solifenacin.

\#Includes OAB-related medication use (anti-depressants, benzodiazepines, hypnotics, laxatives, anti-infective drugs). 


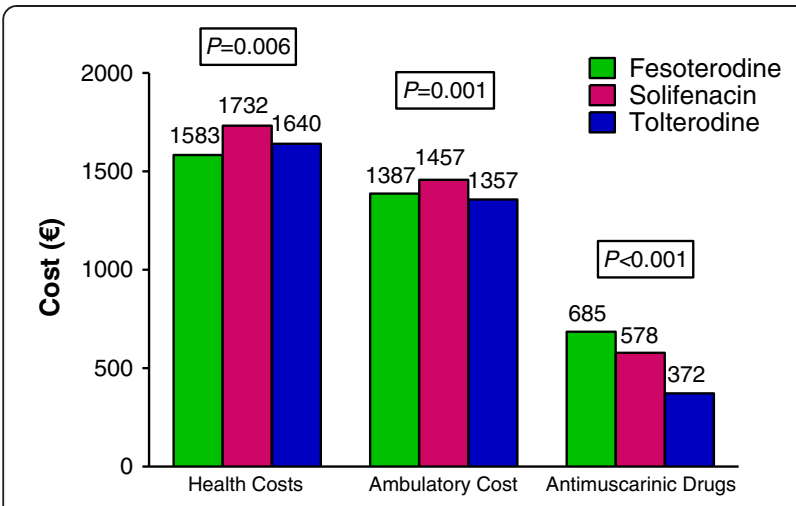

Figure 2 Secondary analysis performed using actual prices for antimuscarinic drugs. Reductions in the costs of antimuscarinic drugs were assumed for this analysis; other components of healthcare costs were kept constant. Health costs included primary (outpatient) and specialized care. Data were adjusted by location, age, sex, medication possession ratio, time since diagnosis and Charlson comorbidity index.

tolterodine. The additional pharmacy costs found in fesoterodine-treated patients were offset by overall lower healthcare use, mostly driven by reductions in medical visits (of all types) and OAB-related concomitant medications compared with solifenacin and tolterodine. After controlling for confounding variables, fesoterodine-treated patients had a significantly lower total annual healthcare cost per patient. This represents an annual per-patient savings of approximately $€ 141$ to the Spanish NHS when compared with solifenacin and approximately $€ 254$ versus tolterodine. From a healthcare decision-making perspective, these savings are substantial in view of the number of patients with $\mathrm{OAB}$ in the NHS. In a secondary analysis, the total annual per-patient costs for fesoterodine were similar to those of tolterodine when the price of tolterodine was reduced by $40 \%$ to reflect current prices subsequent to the loss of patent protection in Spain. Both fesoterodine and tolterodine showed significantly lower total healthcare costs than solifenacin.

The cost advantage of fesoterodine over tolterodine may be explained by its greater efficacy, which may result from pharmacokinetic differences. Fesoterodine has greater bioavailability and therefore a greater possibility of exerting therapeutic effects. The improved efficacy of the higher fesoterodine dose $(8 \mathrm{mg})$ has been established in clinical trials $[22,25,39]$ and primary medical practice [40]; this dose was used by $57 \%$ of patients taking fesoterodine in our study.

In contrast, titration of solifenacin to the higher dose (10 mg) has not been shown to be associated with increased efficacy [41,42]; in our study, $13 \%$ of patients taking solifenacin used the 10-mg dose. A 4-mg dose of tolterodine ER is the only commercially available formulation; $12 \%$ of patients taking tolterodine received a $2-\mathrm{mg}$ twice daily standard (i.e. not extended release) dose. Therefore it is possible that patients taking solifenacin and tolterodine may have received an ineffective dosage in our study. However our results under real-world conditions appear to be consistent with those observed in head-to-head comparative clinical trials. The Fesoterodine Assessment and Comparison Versus Tolterodine (FACT) trials showed that fesoterodine $8 \mathrm{mg}$ is superior in efficacy to tolterodine ER $4 \mathrm{mg}$, with significantly greater reductions in episodes of urgency and urgency with incontinence and a significantly higher proportion of "dry" patients $[24,25,39]$. Likewise, comparative clinical trials of solifenacin versus tolterodine showed these two drugs to be similar in efficacy for the treatment of symptomatic OAB [43].

There are several limitations to this study. Some patients with $\mathrm{OAB}$ may have been excluded because of disease miscoding/misclassification, and some patients diagnosed as having OAB may not have the disease. The risk of disease misclassification was minimized in this study because physicians in participating locations were well trained in medical data recording and the computerized system includes regular quality control testing. Under-recording of healthcare resource use, whether an oversight by healthcare professionals or due to resource use outside of the geographical areas of interest, may have led to an underestimation of total costs. In all cases these potential biases are likely to have affected the three study drugs equally. Direct non-health costs (i.e. out-ofpocket costs paid by the patient that are not funded by the NHS) could not be assessed, because none of the three databases analyzed accounts for these costs. Outof-pocket costs of OAB can be substantial, particularly for non-funded absorbent products. Because only $10 \%$ of the records analyzed were on occupationally active patients, an economic analysis that considers effects on productivity could not be performed. Furthermore it was not possible to assess $\mathrm{OAB}$ severity among patients for any of the antimuscarinic drugs prescribed; significant differences among groups could have influenced outcomes. However the fact that no significant differences in resource use and/or healthcare costs were found in the year prior to the index date suggests that symptom severity was similar among treatment groups.

This study demonstrated that in primary clinical practice in Spain, treatment of OAB with fesoterodine was a costsaving therapy compared with solifenacin or tolterodine in the NHS system, and that the higher cost of fesoterodine therapy could be offset by lower overall healthcare resource use. Fesoterodine was associated with decreased healthcare resource utilization, including medical visits of all types as well as concomitant medications; this reduced utilization translated into significantly lower total annual healthcare costs per patient. Future studies in other healthcare settings are needed to confirm these findings. 


\section{Competing interest}

This study was sponsored by Pfizer Inc. Javier Rejas and Marion Kvasz are employees of Pfizer, S.L.U. and Pfizer PIO, respectively. Antoni Sicras was a paid consultant to Pfizer in connection with the development of this manuscript. Statistical analysis was performed by DataClinics and was funded by Pfizer Inc. All other authors declare that they have no competing interests. Editorial support was provided by Colin Mitchell, PhD, of Complete Healthcare Communications, Inc., and was funded by Pfizer Inc.

\section{Authors' contributions}

All authors had complete access to the data, participated in the analysis and/or interpretation of results, drafted and approved the content of the manuscript. ASM, JR and MK participated in the design and idea of the original study and in the interpretation of data and drafting the manuscript. RNA, AAJ, ART and JIN participated in collection of data and interpretation of statistical analysis results, review of manuscript and important contribution to several parts of the manuscript. All authors were responsible for literature review and extraction of references.

\section{Acknowledgments}

We thank the BSA healthcare professionals who aided this study.

\section{Author details}

'Directorate of Planning, Badalona Serveis Assistencials SA, Calle Gaietà Soler, 6-8 entlo, CP 08911 Badalona, Barcelona, Spain. ${ }^{2}$ Health Economics and Outcomes Research, Pfizer SLU, Alcobendas, Madrid, Spain. ${ }^{3}$ Medical Information Department, Hospital Germans Trias i Pujol, Badalona, Spain. ${ }^{4}$ CAP Sagrada Familia, Barcelona, Spain. ${ }^{5}$ Primary Health Care Directorate, 1ib-Salut, Mallorca, Spain. ${ }^{6}$ Directorate of Badalona Serveis Assistencials SA, Hospital Municipal de Badalona, Badalona, Barcelona, Spain. ${ }^{7}$ Health Economics and Outcomes Research, Pfizer PIO, Paris, France.

Received: 25 June 2013 Accepted: 11 October 2013

Published: 21 October 2013

\section{References}

1. Haylen BT, de Ridder D, Freeman RM, Swift SE, Berghmans B, Lee J, Monga A, Petri E, Rizk DE, Sand PK, Schaer GN: An International Urogynecological Association (IUGA)/International Continence Society (ICS) joint report on the terminology for female pelvic floor dysfunction. Neurourol Urodyn 2010, 29:4-20.

2. Kirby M, Artibani W, Cardozo L, Chapple C, Diaz DC, De Ridder D, Espuna-Pons M, Haab F, Kelleher C, Milsom I, Van Kerrebroeck P. Vierhout M, Wagg A: Overactive bladder: the importance of new guidance. Int J Clin Pract 2006, 60:1263-1271.

3. Latini JM, Giannantoni A: Pharmacotherapy of overactive bladder: epidemiology and pathophysiology of overactive bladder. Expert Opin Pharmacother 2011, 12:1017-1027.

4. Irwin DE, Milsom I, Hunskaar S, Reilly K, Kopp Z, Herschorn S, Coyne K, Kelleher C, Hampel C, Artibani W, Abrams P: Population-based survey of urinary incontinence, overactive bladder, and other lower urinary tract symptoms in five countries: results of the EPIC study. Eur Urol 2006, 50:1306-1315.

5. Milsom I, Abrams P, Cardozo L, Roberts RG, Thuroff J, Wein AJ: How widespread are the symptoms of an overactive bladder and how are they managed? A population-based prevalence study. BJU Int 2001, 87:760-766.

6. Stewart WF, Van Rooyen JB, Cundiff GW, Abrams P, Herzog AR, Corey R, Hunt TL, Wein AJ: Prevalence and burden of overactive bladder in the United States. World J Urol 2003, 20:327-336.

7. Odeyemi IA, Dakin HA, O'Donnell RA, Warner J, Jacobs A, Dasgupta P: Epidemiology, prescribing patterns and resource use associated with overactive bladder in UK primary care. Int J Clin Pract 2006, 60:949-958.

8. Tikkinen KA, Tammela TL, Rissanen AM, Valpas A, Huhtala H, Auvinen A: Is the prevalence of overactive bladder overestimated? A population-based study in Finland. PLOS ONE 2007, 2:e195.

9. Castro D, Espuna M, Prieto M, Badia X: Prevalence of overactive bladder in Spain: a population-based study. Arch Esp Urol 2005, 58:131-138.

10. Martinez Agullo E, Ruiz Cerda JL, Gomez Perez L, Ramírez Backhaus M, Delgado Oliva F, Rebollo P, González-Segura Alsina D, Arumi D: Prevalence of urinary incontinence and hyperactive bladder in the Spanish population: results of the EPICC study. Actas Urol Esp 2009, 33:159-166.

11. Sexton CC, Coyne KS, Thompson C, Bavendam T, Chen Cl, Markland A: Prevalence and effect on health-related quality of life of overactive bladder in older americans: results from the epidemiology of lower urinary tract symptoms study. J Am Geriatr Soc 2011, 59:1465-1470

12. Vaughan CP, Johnson TM 2nd, Ala-Lipasti MA, Cartwright R, Tammela $T L$, Taari K, Auvinen A, Tikkinen KA: The prevalence of clinically meaningful overactive bladder: bother and quality of life results from the population-based FINNO study. Eur Urol 2011, 59:629-636.

13. Yoo ES, Kim BS, Kim DY, Oh SJ, Kim JC: The impact of overactive bladder on health-related quality of life, sexual life and psychological health in Korea. Int Neurourol I 2011, 15:143-151.

14. Martinez Agullo E, Ruiz Cerda JL, Gomez Perez L, Rebollo P, Perez M, Chaves J Impact of urinary incontinence and overactive bladder syndrome on health-related quality of life of working middle-aged patients and institutionalized elderly patients. Actas Urol Esp 2010, 34:242-250.

15. Bartoli S, Aguzzi G, Tarricone R: Impact on quality of life of urinary incontinence and overactive bladder: a systematic literature review. Urology 2010, 75:491-500.

16. Irwin DE, Milsom I, Kopp Z, Abrams P: Symptom bother and health care-seeking behavior among individuals with overactive bladder. Eur Urol 2008, 53:1029-1037.

17. Benner JS, Becker R, Fanning K, Jumadilova Z, Bavendam T, Brubaker L: Bother related to bladder control and health care seeking behavior in adults in the United States. J Urol 2009, 181:2591-2598.

18. Andersson KE: Antimuscarinic mechanisms and the overactive detrusor: an update. Eur Urol 2011, 59:377-386.

19. Hunter KF, Wagg A, Kerridge T, Chick $H$, Chambers T: Falls risk reduction and treatment of overactive bladder symptoms with antimuscarinic agents: a scoping review. Neurourol Urodyn 2011, 30:490-494.

20. Swinburn P, Lloyd A, Ali S, Hashmi N, Newal D, Najib H: Preferences for antimuscarinic therapy for overactive bladder. BJU Int 2011, 108:868-873

21. Dobrek L, Juszczak K, Wyczolkowski M, Thor PJ: Current management and future perspectives of overactive bladder (OAB) pharmacotherapy. Acta Pol Pharm 2011, 68:807-821.

22. Chapple C, Van Kerrebroeck P, Juenemann K, Wang J, Brodsky M: Comparison of fesoterodine and tolterodine in subjects with overactive bladder. BJU Int 2008, 102:1128-1132.

23. Chapple C, Van Kerrebroeck P, Tubaro A, Haag-Molkenteller C, Forst HT, Massow U, Wang J, Brodsky M: Clinical efficacy, safety, and tolerability of once-daily fesoterodine in subjects with overactive bladder. Eur Urol 2007, 52:1204-1212.

24. Corcos J, Angulo JC, Garely AD, Carlsson M, Gong J, Guan Z: Effect of fesoterodine $4 \mathrm{mg}$ on bladder diary and patient-reported outcomes during the first week of treatment in subjects with overactive bladder. Curr Med Res Opin 2011, 27:1059-1065.

25. Herschorn S, Swift S, Guan Z, Carlsson M, Morrow JD, Brodsky M, Gong J: Comparison of fesoterodine and tolterodine extended release for the treatment of overactive bladder: a head-to-head placebo-controlled trial. BJU Int 2010, 105:58-66.

26. Nitti WW, Dmochowski R, Sand PK, Forst HT, Haag-Molkenteller C, Massow U, Wang J, Brodsky M, Bavendam T: Efficacy, safety and tolerability of fesoterodine for overactive bladder syndrome. J Urol 2007, 178:2488-2494.

27. Kelleher CJ, Tubaro A, Wang JT, Kopp Z: Impact of fesoterodine on quality of life: pooled data from two randomized trials. BJU Int 2008, 102:56-61.

28. Sexton CC, Notte SM, Maroulis C, Dmochowski RR, Cardozo L, Subramanian D, Coyne KS: Persistence and adherence in the treatment of overactive bladder syndrome with anticholinergic therapy: a systematic review of the literature. Int J Clin Pract 2011, 65:567-585.

29. Benner JS, Nichol MB, Rovner ES, Jumadilova Z, Alvir J, Hussein M, Fanning K, Trocio JN, Brubaker L: Patient-reported reasons for discontinuing overactive bladder medication. BJU Int 2010, 105:1276-1282.

30. Watanabe JH, Campbell JD, Ravelo A, Chancellor MB, Kowalski J, Sullivan SD: Cost analysis of interventions for antimuscarinic refractory patients with overactive bladder. Urology 2010, 76:835-840,

31. Reeves P, Irwin D, Kelleher C, Milsom I, Kopp Z, Calvert N, Lloyd A: The current and future burden and cost of overactive bladder in five European countries. Eur Urol 2006, 50:1050-1057. 
32. Mullins CD, Subak LL: New perspectives on overactive bladder: quality of life impact, medication persistency, and treatment costs. Am J Manag Care 2005, 11 (4 Suppl):S101-S102.

33. WHO Collaborating Centre for Drug Statistics Methodology: Anatomic Therapeutic Chemical classification system: structure and principles. Available at: http://www.whocc.no/atc/structure_and_principles/\#structure. Accessed: March 13, 2013.

34. Steiner JF, Prochazka AV: The assessment of refill compliance using pharmacy records: methods, validity, and applications. J Clin Epidemiol 1997, 50:105-116.

35. Benner JS, Glynn RJ, Mogun H, Neumann PJ, Weinstein MC, Avorn J: Long-term persistence in use of statin therapy in elderly patients. JAMA 2002, 288:455-461.

36. The International Classification of Primary Care in the European Community: With a Multi-language Layer. Oxford: Oxford Medical Publications; 1993.

37. Charlson ME, Pompei P, Ales KL, Mackenzie CR: A new method of classifying prognostic comorbidity in longitudinal studies: development and validation. J Chronic Dis 1987, 40:373-383.

38. Thompson SG, Barber JA: How should cost data in pragmatic randomised trials be analysed? BMJ 2000, 320:1197-1200.

39. Kaplan SA, Schneider T, Foote JE, Guan Z, Carlsson M, Gong J: Superior efficacy of fesoterodine over tolterodine extended release with rapid onset: a prospective, head-to-head, placebo-controlled trial. BJU Int 2011, 107:1432-1440.

40. Castro-Diaz D, Miranda P, Sanchez-Ballester F, Lizarraga I, Arumi D, Rejas J: Dose and aging effect on patients reported treatment benefit switching from the first overactive bladder therapy with tolterodine Er to fesoterodine: post-hoc analysis from an observational and retrospective study. BMC Urol 2012, 12:19.

41. Cardozo L, Lisec M, Millard R, van Vierssen TO, Kuzmin I, Drogendijk TE, Huang M, Ridder AM: Randomized, double-blind placebo controlled trial of the once daily antimuscarinic agent solifenacin succinate in patients with overactive bladder. J Urol 2004, 172:1919-1924.

42. Chapple CR, Rechberger T, Al-Shukri S, Meffan P, Everaert K, Huang M, Ridder A: Randomized, double-blind placebo- and tolterodine-controlled trial of the once-daily antimuscarinic agent solifenacin in patients with symptomatic overactive bladder. BJU Int 2004, 93:303-310.

43. Chapple CR, Martinez-Garcia R, Selvaggi L, Toozs-Hobson P, Warnack W, Drogendijk T, Wright DM, Bolodeoku J: A comparison of the efficacy and tolerability of solifenacin succinate and extended release tolterodine at treating overactive bladder syndrome: results of the STAR trial. Eur Urol 2005, 48:464-470.

doi:10.1186/1471-2490-13-51

Cite this article as: Sicras-Mainar et al:: Health economics perspective of fesoterodine, tolterodine or solifenacin as first-time therapy for overactive bladder syndrome in the primary care setting in Spain. BMC Urology 2013 13:51.

\section{Submit your next manuscript to BioMed Central and take full advantage of:}

- Convenient online submission

- Thorough peer review

- No space constraints or color figure charges

- Immediate publication on acceptance

- Inclusion in PubMed, CAS, Scopus and Google Scholar

- Research which is freely available for redistribution 